\title{
PROPOSAL OF ALGORITHM FOR ROUTE OPTIMIZATION
}

\author{
PROPOSTA DE ALGORITMO PARA UTILIZAÇÃO DE ROTAS
}

Robert Ramon de Carvalho Sousa ${ }^{1}$; Abimael de Jesus Barros Costa ${ }^{1}$; Eliezé Bulhões de Carvalho ${ }^{1}$; Adriano de Carvalho Paranaíba ${ }^{1}$; Daylyne Maerla Gomes Lima Sandoval ${ }^{1}$

${ }^{1}$ Universidade de Brasília - Programa de Pós-graduação em Transportes Departamento de Engenharia Civil e Ambiental

robert.carvalho247@gmail.com, professor.abimael@gmail.com, eliezec@gmail.com, adr.paranaiba@gmail.com, daylynemaerla@gmail.com

ABSTRACT - This article uses "Six Sigma" methodology for the elaboration of an algorithm for routing problems which is able to obtain more efficient results than those from Clarke and Wright's (CW) algorithm (1964) in situations of random increase of product delivery demands, facing the incapability of service level increase. In some situations, the algorithm proposed obtained more efficient results than the $\mathrm{CW}$ algorithm. The key factor was a reduction in the number of mistakes (one way routes) and in the level of result variation.

Recebido em: 10/11/2015 Keywords: route optimization; Six Sigma; methodology; Clarke and Revisado em: 22/06/2016 Aprovado em: 01/09/2016 


\section{INTRODUCTION}

O According to Laporte et al. (2000), the vehicle routing problem is the choice of routes to be travelled by vehicles, so that these match every point exactly once, and that the demand on each trip does not exceed the maximum capacity of the vehicle at the lowest possible total cost. To Hall and Partyka (1997), the proposed heuristic calculations require robustness, i.e. they are unable to obtain the best results for problems with conditioning features or restrictions other than those in which the model was developed.

Among the main methods proposed in the literature, it is the algorithm of Clarke and Wright (1964) (CW) that solves problems of vehicles routing through an algorithm which defines the routes based on the greatest gained distance. This method is able to provide very efficient results. According to Ballou (2006), its solutions are, on average, two percent more expensive than the optimum level. To Hensher and Button (2008), the models applied to transport, which appeared between the 50s and 60s, had intended to resolve essentially practical problems, where the focus was just to improve the systems performance. However, currently the transport modeling study seeks to formulate models and algorithms that consider the influence of economic factors behavior, including the costs and the relationship between supply and demand.

Several authors have proposed algorithms to improve the performance of freight delivery systems, among them Dror and Levy (1986), which from a vehicle routing problem (VRP) presented three heuristics of improvement able to examine and operate all routes concurrently through our concept of exchange.

Nevertheless, Larson (1988) proposed a method based on the $\mathrm{CW}$ heuristic, which considers fixed routes for the collection of waste from sewage treatment plants, where the demands follow a normal distribution, but are treated as deterministic. The end result is a frequency of visits far greater than necessary for some customers. In parallel, Benjamin (1989) presented a heuristic for solving nonlinear problems starting from the problem of economic transport and batch determination of request, such resolution was only suitable for smaller instances.

One of the most notorious heuristics is the one of Chien et al. (1989), which deal with an entire mixed programming model that allocates the factory inventory distribution to customers, groups customers in routes and routes it. The problem of multiperiod is decomposed into sub problems series of a single period, using objective function of a single period. In parallel, 
Speranza and Ukovick (1994) studied the distribution of multiple products through whole or mixed linear programming.

Most recently, Campbell and Savelsbergh (2004) detailed the problem in two steps. The first is to determine the quantities to be delivered to customers, the days of attendance and the designation of the results obtained through the entire mixed programming. The second one determines the effective programming of the routes from the results obtained in the first phase. At the end it becomes a daily routing that will subsequently subsidize a weekly routing.

The literature shows several studies that seek to find solutions for the problem of routing considering economic factors that impact on the performance of distribution systems. Therefore, the objective of this article is to apply the logic of the quality management program "Six Sigma" to observe the errors on Clarke and Wright's algorithm (1964) and thus, to propose an algorithm capable to find better results in a simulation that aims to reflect a situation of increasing demand randomly front deliverability static. The characteristics of the simulations were specified in order to better understand the influence of the relationship between capacity and demand on the results from Clarke and Wright (1964).

\section{CLARKE AND WRIGHT'S ROUTING}

\section{ALGORITHM}

According to Ballou (2006), CW method has been considered a model capable of solving problems of routing decisions in various restrictive situations with practices and rapid solutions for years, its logic is applied in several studies in the area of transport and business logistics. Authors such as: Johnson and Mcgech (1995); Battarra, Golden and Vigo (2008) worked on the analysis of the calculation logic and application of a model on distribution solutions. In addition, Cunha, Bonasser and Abrahão (2002) examined specific aspects of computational implementation of heuristics of improvements that influence the quality of the results obtained in the processing times.

The algorithm model by Clarke and Wright (1964) starts the analysis considering that the adoption of the worst possible solution is one in which every point is attended individually within a route. The total distance $(\mathrm{L})$ is given by Equation 1:

$L=2 d D, i$

Where: $d D, i$ is the distance between the warehouse $D$ and the client $i$, as Figure 1 . 


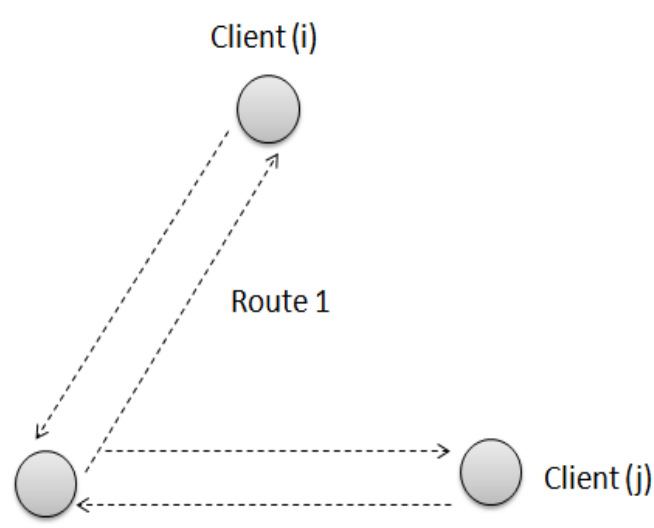

Warehouse-Point (p) Route 2

Figure 1 - Delivery routes to only one point of delivery at a time.

Source: (Clarke and Wright, 1964).

However, there is the possibility to perform deliveries at two or more points in the same route. Hence, there is a reduction in mileage rates and that generates efficiency gains. The calculation is given by Equation 2:

$$
\begin{aligned}
S i, j & =L a-L b \\
& =2 \cdot d_{D, i}+2 d \\
& \\
D, j- & {\left[d_{D, i}+d_{1, j}+d_{D, j}\right] } \\
= & d_{D, i}+d_{D, j}-d_{i, j}
\end{aligned}
$$

Clarke and Wright (1964) perform the calculation of gains in distance and arrange a sequence of possible combinations, these should be collated in a row starting with the pairs of further reduction of $\mathrm{Si}, \mathrm{j}$. The distance and journey time are calculated for each route option and compared with the restrictions. The routes are chosen as they meet the restrictions. To Ballou (2006), it should be taken into account the greater economic value identified for inclusion of a new route, if the time constraint and the ability of the vehicle do not meet, then the combination with the next value of economy shall be considered.

\section{THEORETICAL BASES OF THE PROPOSED}

\section{ALGORITM}

The proposed algorithm which will be elaborated for the use of quality management methodology is the "Six Sigma".

The logic of "Six Sigma" consists of analyzing the results of a process, identifying aspects that require adjustments, proposing partial or full settings and finally, measuring and comparing the results of both processes with the use of statistical techniques. By adopting methods or improved processes to obtain the best performance of any system, in practice the main measures aim to reduce both the number of errors in the process regarding the variability of the results.

To Montgomery (2004), the purpose of the "Six Sigma" in statistical terms is to reduce the variability of results and the level of errors. The positive effect of such changes has theoretical support. According to several authors (BAÑUELAS AND ANTONY, 2002; FOLARON, 2000; HAHN et al., 2000; LIDERMAN et al., 2003; PFEIFER et al., 2004; WESSEL AND BURGUER, 2004), the methodology "Six Sigma" can provide the increase of enterprises competitiveness and 
the reduction of production costs through the decrease in the number of defective items, diminution of process times and improvement those that already exist.

To Wheeler (2002), the metrics used in the "Six Sigma" observe the defects more efficiently than those used in classical quality programs, such as metrics. According to Wheeler (2002) and Lucas (2002), they are presented below:

a) Defects per unit (dpu): is a measure that reflects the average number of defects of all kinds in the total number of units produced. The dpu can be calculated according to Equation (3).

$\mathrm{dpu}=($ no faults) $/$ (no units)

b) defects per opportunity (dpo): in dpo it is expressed the proportion of defects taking into consideration the total number of opportunities during the process, for the occurrence of defects, this being calculated by Equation (4).

Dpo $=(\mathrm{n}$ defects $) /(\mathrm{n}$ de units $* \mathrm{n}$ opportunities $)=(\mathrm{dpu}) /(\mathrm{n}$ de opportunities $)(4)$

c) defects per million opportunities (dpmo): the dpmo indicates the number of defects that can occur in a million possible opportunities for the occurrence of defects (Equation 5).
Dpmo $=d p o * 106$

The variables of the problem are:

$\mathrm{N}$ units = total number of obtained routes .

$\mathrm{N}$ opportunities $=$ total number of opportunities routes obtained.

Defects $=$ total number of single delivery routes.

Marash (2000) explains that the "Six Sigma" is the best performance to be obtained, where the number of defects per million opportunities is equal to 3.4 . This corresponds to an error-free percentage equivalent to $99.999966 \%$. The higher the sigma level, the better the quality of the system. The Table 1 shows sigma levels and their respective amounts of defects per million.

Table 1. Table of sigma levels table according to the number of defects per million (dpmo).

\begin{tabular}{|r|c|}
\hline Sigma Level & $\begin{array}{c}\text { Defects for one million of } \\
\text { opportunities (Dpmo) }\end{array}$ \\
\hline 1 & 691.462 \\
\hline 2 & 308.537 \\
\hline 3 & 66.807 \\
\hline 4 & 6.210 \\
\hline 5 & 233 \\
\hline 6 & 3,4 \\
\hline
\end{tabular}

Source: (LUCIER AND SECHADRI, 2001).

In a complementary manner for the analysis of the results, Breyfogle (1999) proposes the calculation First Throughput Yield (FTY), which measures the pinpoint 
process yield indicating the probability of obtaining zero defects in each specific step, by Equation (6).

$\mathrm{FTY}=\mathrm{P}(\mathrm{X}=0)=\mathrm{e}-\mathrm{DPU}$

In addition to this calculation, Werkema (2002) and Pande, Neuman and Cavanagh (2002) propose the Rolled Throughput Yield (RTY), which represents the probability of a single product going through several processes and coming out of them with zero defects, as Figure 7. :

FTY $=1-[($ units of scrap + unitsworked $) /($ input units)]

According to Werkema (2002), the RTY can also be obtained by multiplying the FTY of each step of the process, as Figure 8.

RTY $=$ FTY1 $x$ FTY $2 \times \ldots \times$ FTYn

Lobos (1991) affirms that the provision "zero error" is not a utopia but rather a way of thinking capable of delivering productivity gains. In any case there is the combination of faulty and not faulty components that suit over several processes can lead to a significant number of results capable of compromising the final results, as Equation 9:

$$
\text { RTY }=\text { FTY1 } \times \text { FTY2 } \times \ldots \times \text { FTYn }
$$

Breyfogle (1999) exposes the Equation (10) to calculate the final yield of the processes.

Yfinal $=1-D P U$

Harry (1998) states that a high value of standard deviation corresponds to a low probability of getting defects in the process, so it will be calculated the standard deviation of the results of the total route time, the mileage travelled and the number of separate routes through the Equation 11 below.

$$
\mathrm{S}=\sqrt{\frac{\sum(x \vec{i}-\vec{x})^{2}}{n-1}}
$$

Display and comparison of results will be made with the aid of Pareto Diagram and graphs of Normal Distribution.

\section{METHODOLOGY}

The work consists of a case study with fictitious data in which will be held 11 simulations with the algorithm Clarke and Wright (1964) and the proposed algorithm to compare the results. The methodology and the main statistical tools of "Six Sigma" will be applied. The steps are: 
a) analysis of the simulation results with Clarke and Wright's algorithm (1964);

b) identification of aspects requiring adjustments in the logic of the calculation;

c) proposal of an algorithm and perform simulations using the same data and restrictive parameters; and

d) comparison of the results of both processes with the use of the main "Six Sigma" statistical techniques.

\section{CASE STUDY AND SIMULATIONS WITH} CLARKE AND WRIGHT'S ALGORITHM (1964)

A case study regarding fictitious cargo carrier company "Mega Transportes", located in the city of Brasilia-DF, will be conducted. The company is at the beginning of its operations and currently, it has only one truck with capacity to carry up to 4 tons. The company's financial situation is fragile, due to the initial investment in structure, advertising and working capital necessary to cover shortterm obligations.

The investment in advertising is generating good results and the demand of existing customers is increasing constantly. On average there is the increase of 0.5 tons of loads with each new delivery demand. The Manager of the company intends to adopt a scripting system and is seeking some calculation logic capable of achieving the best possible results for the current situation in which the company finds itself.
Aiming to establish a calculation logic that meets the current needs of the company Mega Transportes, 11 simulations by means of the logic of the Clarke and Wright's model will be held (1964), where each simulation will have an increase of 0.5 tones.

Table 2. Problem data.

\begin{tabular}{|c|c|c|c|}
\hline Delivery Points & Location & Ton for week & Discharge Time \\
\hline 1 & CLN 112 & 3,5 & 40 \\
\hline 2 & CLN 315 & 1,5 & 60 \\
\hline 3 & CLN 413 & 0,2 & 90 \\
\hline 4 & W3 NORTE 707 & 0,7 & 20 \\
\hline 5 & W3 NORTE713 & 2,5 & 50 \\
\hline 6 & CLS 102 & 2,8 & 50 \\
\hline 7 & CLS 302 & 1,8 & 30 \\
\hline 8 & CLS 405 & 2 & 90 \\
\hline 9 & CLS 203 & 1,3 & 60 \\
\hline 10 & CLS209 & 1,2 & 60 \\
\hline Full Demand & & 17,5 & \\
\hline Full Capacity & & 4 ton & \\
\hline Maximum Delivery Time & & 12 hours & \\
\hline Average Speed & & $40 \mathrm{~km} /$ hour & \\
\hline Starting Point & \multicolumn{3}{|c|}{ Depósito - Setor de Indústria- Feira dos Importados } \\
\hline
\end{tabular}

The data that compound the decision problem of routes used in the simulations are based on:

a) the demands of delivery;

b) the discharge time; and

c) fictitious delivery points relating to the city of Brasilia-DF (Table 2).

The actual values of the distances between the points of delivery were found with the help of Google Maps software, according to Table 3. 
Table 3. Distances between two points.

\begin{tabular}{|c|c|c|c|c|c|c|c|c|c|}
\hline $\mathbf{1}$ & $\mathbf{2}$ & $\mathbf{0}$ & $\mathbf{4}$ & $\mathbf{5}$ & $\mathbf{6}$ & $\mathbf{7}$ & $\mathbf{8}$ & $\mathbf{9}$ & $\mathbf{1 0}$ \\
\hline 26,67 & 40 & 60 & 13,33 & 33,33 & 33,33 & 20 & 60 & 40 & 40 \\
\hline $\mathrm{X}$ & 1,9 & 2,1 & 6,5 & 6,5 & 6,3 & 6,9 & 8,8 & 7,4 & 9,5 \\
\hline & $\mathrm{X}$ & 1,8 & 6,8 & 6,8 & 7,6 & 7,2 & 10,2 & 8,7 & 11,4 \\
\hline & & $\mathrm{X}$ & 8,2 & 8,2 & 8,1 & 8,6 & 8,7 & 8,6 & 10,9 \\
\hline & & & $\mathrm{X}$ & 0,3 & 4,2 & 3,9 & 7 & 5,3 & 7,5 \\
\hline & & & & $\mathrm{X}$ & 6,2 & 5,9 & 9,1 & 7,3 & 9,5 \\
\hline & & & & & $\mathrm{X}$ & 0,9 & 2,3 & 1,5 & 3,4 \\
\hline & & & & & & $\mathrm{X}$ & 2,6 & 1,8 & 3,8 \\
\hline & & & & & & & $\mathrm{X}$ & 1,7 & 2,5 \\
\hline & & & & & & & & $\mathrm{X}$ & 2,8 \\
\hline & & & & & & & & & $\mathrm{X}$ \\
\hline
\end{tabular}

After raising distances, were

calculated the gains in distance between the points, based on Clarke and Wright's literature (1964), as Equation 12.

$S i, j=d_{D, p i}+d_{D, p j}-d_{i, j}$

The results of total travelling time and total distance travelled are set out in Table 4. Each system corresponds to the attendance of all points of demand. Each one was calculated by means of the increase of 0.5 tons in any delivery point at random, so that all points obtained at least one increase along the 11 simulations. You can verify that each delivery system has a pattern that characterizes it: System 1 has a route N3, three routes N2 and one N1 route, unlike the pattern observed in the System 2, which consists of two routes N3, zero routes N2 and four routes N1, where N3 = number of routes with connection between 3 points, N2 = number of routes with connection between 2 points and $\mathrm{N} 1$ = number of single delivery routes, as Table 4.

Table 4. Results of simulations.

\begin{tabular}{|l|r|r|r|r|r|}
\hline CLARK and WRIGHT & N 3 & N 2 & N 1 & Time $(\mathrm{h})$ & Distance ( Km) \\
\hline System 1 (18,0 ton) & 1 & 3 & 1 & 18,11 & 357,83 \\
\hline System 2 (18,5 ton) & 2 & 0 & 4 & 19,95 & 426,37 \\
\hline System 3 (19,0 ton) & 1 & 2 & 3 & 19,17 & 399,97 \\
\hline System 4 (19,5 ton) & 1 & 2 & 3 & 19,17 & 399,97 \\
\hline System 5 (20,0 ton) & 1 & 2 & 3 & 20,62 & 458,13 \\
\hline System 6 (20,5 ton) & 0 & 4 & 2 & 20,39 & 442,47 \\
\hline System 7 (21,0 ton) & 0 & 4 & 2 & 20,39 & 442,47 \\
\hline System 8 (21,5 ton) & 0 & 3 & 4 & 22,05 & 509,00 \\
\hline System 9 (22,0 ton) & 0 & 3 & 4 & 22,05 & 509,00 \\
\hline System 10 (22,5 ton) & 0 & 3 & 4 & 22,05 & 509,00 \\
\hline System 11 (23,0 ton) & 0 & 3 & 4 & 22,38 & 528,50 \\
\hline
\end{tabular}

The simulation results show that there is a direct relationship between the quantity of single delivery routes and the results of time and distance. This can illustrate as follows: System 1 obtained a single delivery route and obtained better results than the System 6, which obtained 2 single delivery routes in the composition of its default. The more single delivery routes, the smaller the reduction of distance and time. Therefore, it can be affirmed that the single delivery routes are decision errors and impact negatively on the performance of any freight delivery system.

\section{RELEVANT ASPECTS}

The results of the simulations show that Clarke and Wright's algorithm (1964) is highly sensitive to increased demand, since the composition of their routes required 
more frequent adjustments. The first step of the calculation algorithm shows that the gains hierarchy is used to decide all combinations between two possible points, this is based on the reduction of distance without the influence of variables: capacity to offer services, demand for delivery of the products and maximum acceptable time.

In the second step it is necessary to check if the first combination proposed by the distance gains hierarchy follows the time and capacity constraints. Finally, it is needed to see if there is the possibility of including one or more delivery points on the same route without exceeding the restrictions.

There are two issues to be highlighted when you perform a critical analysis of the steps of Clarke and Wright's algorithm calculation (1964). The first one refers to the hierarchy of gains in distance. If they are kept at the same points of delivery of goods, probably the same "hierarchy of gains in distance" will be obtained, this is because the distance between the deposit and each delivery point hardly changes.

The second issue refers to the variables: supply capacity in services and demand for products. These are constantly changing due to several market factors, however, they are used only as a qualifying character or an eliminatory one to decide the composition of each route.
More restrictive levels led Clarke Wright's algorithm (1964) to adopt more single delivery routes, this fact decreases its ability to reduce the distances covered. Consequently, it is possible to infer that the elasticity of supply capacity in services and demand is a factor that also influences the compositions of the routes.

\section{PROPOSAL OF THE ALGORITHM AND ITS APPLICATION}

In order to solve the inconsistencies observed in the results of the simulations with Clarke and Wright's algorithm (1964), it is proposed a new algorithm that fulfills two goals. The first is to obtain a smaller number of single delivery routes, aimed at the least total distance travelled and the lowest total travelling time.

The second goal is to establish the composition of possible links between two points with the influence of variables: demand, supply capacity, service time and gain in distance.

a) To achieve the first objective, a way to avoid possible routes of single delivery will be adopted. For that, one should seek possible links to points with delivery demand, shown as it follows: Hierarchize delivery points taking into account their respective demand values in tones $(\mathrm{t})$.

The string should be ordered in descending mode - the result must be a 
"hierarchy of points with greater demand ':

Point 1-3.5 t; Point 6-2.8 t; Point $5-2.5 \mathrm{t}$;

Point 8-2.0 t; Point $7-1.8$ t; Point 2-1.5 t;

Point 9-1.3 t; Point 10-1.2 t; Point $4-0.7$ t;

Point $3-0.2$ t. Links for each point of delivery

in accordance with the sequence established will be listed.

To accomplish the second objective, you must:

Table 5. Possible combinations.

\begin{tabular}{|l|l|l|l|}
\hline Location 1 & Location2 & Possible Combinations & Full Demand \\
\hline \multirow{4}{*}{ First Point } & Point $X$ & First Point + Point $X$ & $\Sigma$ Demand $\leq$ High Capacity \\
\cline { 2 - 4 } & Point $Y$ & First Point + Point $Y$ & $\Sigma$ Demand $\leq$ High Capacity \\
\cline { 2 - 4 } & Point $Z$ & First Point + Point $Z$ & $\Sigma$ Demand $\leq$ High Capacity \\
\hline
\end{tabular}

The possible combinations which extrapolate the maximum capacity will be disregarded, leaving only those that obtain the sum of demands less than or equal to the maximum capacity. The possible combinations that extrapolate the maximum capacity will be disregarded, leaving only those which obtained the sum of demands less than or equal to the maximum capacity.

c) Calculate the total distance to be covered and the total travelling time of each possible combination (Equation 13). The combinations that do not meet the restrictions of time shall be disregarded:

$T(i, j)=[($ Doi + Dij + Djo $) /$ Average speed $]+$ downtime

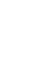

b) List all possible combinations for the first point of the "hierarchy of points with greater demand," according to capacity constraints, as Table 5. 
case study calculated by Clarke and Wright's algorithm (1964), previously presented.

Thus, the first combination can be explained by the following matrix representation: $\mathrm{A} 13$ can combine with $\mathrm{A} 33$; A14 can combine with A34; A15 can combine with $A 35, A 36, A 37 ; A 16$ can combine with A38, A39 and A310; A17 can combine with A311. Thereby, it is accomplished the composition of each route, where the grey horizontal stripes symbolize the combinations chosen by the model, as Table 6.

Table 6. Possible Combinations between two points.

\begin{tabular}{|c|c|c|c|c|c|c|c|}
\hline \multicolumn{7}{|c|}{ Combinations } \\
\hline Location 1 & Demand (ton) 1 & Location 2 & Demand (ton) 2 & Demand (ton) & Cobination & Position in the Distance Gains Hierarchy & Chosen Route \\
\hline Point 1 & 3,5 & Point 3 & 0,2 & $3,7<4,0$ & 513 & 130 & $X$ \\
\hline Point6 & 2,8 & Point4 & 0,7 & $3,5<4,0$ & 546 & $42^{0}$ & $X$ \\
\hline \multirow{3}{*}{ Point5 } & \multirow{3}{*}{2,5} & Point2 & 1,5 & $4,0=4,0$ & 525 & 210 & $X$ \\
\cline { 3 - 8 } & & Point9 & 1,3 & $3,8<4,0$ & 559 & 230 & \\
\cline { 3 - 8 } & & Point 10 & 1,2 & $3,7<4,0$ & 5510 & 270 & \\
\hline \multirow{3}{*}{ Point8 } & \multirow{3}{*}{2} & Point 7 & 1,8 & $3,8<4,0$ & 578 & 140 & \\
\cline { 3 - 8 } & & Point9 & 1,3 & $3,3<4,0$ & 589 & $2^{\circ}$ & \\
\cline { 3 - 8 } & & Point 10 & 1,2 & $3,2<4,0$ & 5810 & 40 & $X$ \\
\hline Point7 & 1,8 & Point 10 & 1,2 & $3,0<4,0$ & 5710 & 320 & \\
\hline
\end{tabular}

The end result of this simulation resulted in a system consisting of the following routes of delivery: S13; S46; S25; S89 and S710.

\section{COMPARISON BETWEEN THE TWO ALGORITHMS}

For comparison purposes, the same amount of simulations for both algorithms (proposed and the Clarke-Wright's), using the same data and constraints of the problem was conducted. The results are detailed in Table 8, where:
$\mathrm{N} 3=$ number of routes with connection between 3 points.

$\mathrm{N} 2$ = number of routes with connection between 2 points.

$\mathrm{N} 1$ = number of delivery routes only.

Dark grey $=$ highest numeric value .

Light grey $=$ lowest numeric value. 
Table 7. Comparing results.

\begin{tabular}{|c|c|c|c|c|c|c|c|c|c|c|c|}
\hline Clarke and Wright & N3 & $\mathrm{N} 2$ & N1 & Time (h) & Distance $(\mathrm{km})$ & Proposal of Algorithm & N3 & $\mathrm{N} 2$ & N1 & Time (h) & Distance $(\mathrm{km})$ \\
\hline System $1(18,0$ ton $)$ & 1 & 3 & 1 & 18,11 & 357,83 & System 1 ( 18,0 ton $)$ & 0 & 5 & 0 & 18,77 & 385,26 \\
\hline System 2(18,5ton) & 2 & 0 & 4 & 19,95 & 426,37 & System 2 (18,5 ton) & 0 & 5 & 0 & 18,77 & 385,26 \\
\hline System 3(19,0ton) & 1 & 2 & 3 & 19,17 & 399,97 & System $3(19,0$ ton $)$ & 0 & 5 & 0 & 18,77 & 385,26 \\
\hline System 4 (19,5ton) & 1 & 2 & 3 & 19,17 & 399,97 & System 4 ( 19,5 ton) & 0 & 5 & 0 & 18,77 & 385,26 \\
\hline System 5(20,0ton) & 1 & 2 & 3 & 20,62 & 458,13 & System $5(20,0$ ton $)$ & 0 & 4 & 2 & 19,81 & 427,06 \\
\hline System 6(20,5 ton) & 0 & 4 & 2 & 20,39 & 442,47 & System 6 (20,5 ton) & 0 & 4 & 2 & 19,81 & 427,06 \\
\hline System 7(21,0ton) & 0 & 4 & 2 & 20,39 & 442,47 & System 7 ( 21,0 ton) & 0 & 4 & 2 & 19,81 & 427,06 \\
\hline System $8(21,5$ ton $)$ & 0 & 3 & 4 & 22,05 & 509 & System 8 (21,5 ton) & 0 & 4 & 2 & 20,43 & 451,76 \\
\hline System $9(22,0$ ton $)$ & 0 & 3 & 4 & 22,05 & 509 & System $9(22,0$ ton) & 0 & 3 & 4 & 22,09 & 518,09 \\
\hline System $10(22,5$ ton $)$ & 0 & 3 & 4 & 22,05 & 509 & System 10 (22,5 ton) & 0 & 3 & 4 & 22,68 & 541,46 \\
\hline System $11(23,0$ ton $)$ & 0 & 3 & 4 & 22,38 & 528,5 & System 11 (23,0ton) & 0 & 3 & 4 & 19,16 & 447,36 \\
\hline
\end{tabular}

The results show that the proposed algorithm is more efficient than CW's algorithm in terms of processing time and distance travelled in 8 of the 11 simulations performed. A relevant factor for obtaining such results was a reduction in the number of single delivery routes. However, the algorithm was less efficient in systems 1, 9 and 10.

The result from System 1 can be justified by the efficiency in distance reduction obtained by Clarke and Wright's algorithm (1964) when creating a route of delivery of 3 points. This one was able to be more efficient in terms of time and distance, despite having presented a single delivery route.
However, in Systems 9 and 10, there was the same pattern ( 3 routes N2 and 4 routes N1) for both algorithms. Clarke and Wright's algorithm (1964) showed the best performance, it was because the number of routes $\mathrm{N} 1$ is equal for both and the Clarke and Wright's logic (1964) which aims to compose combinations taking into account gains in distance presented more efficiently. Figure 2 illustrates the total number of single delivery routes obtained in simulations. 


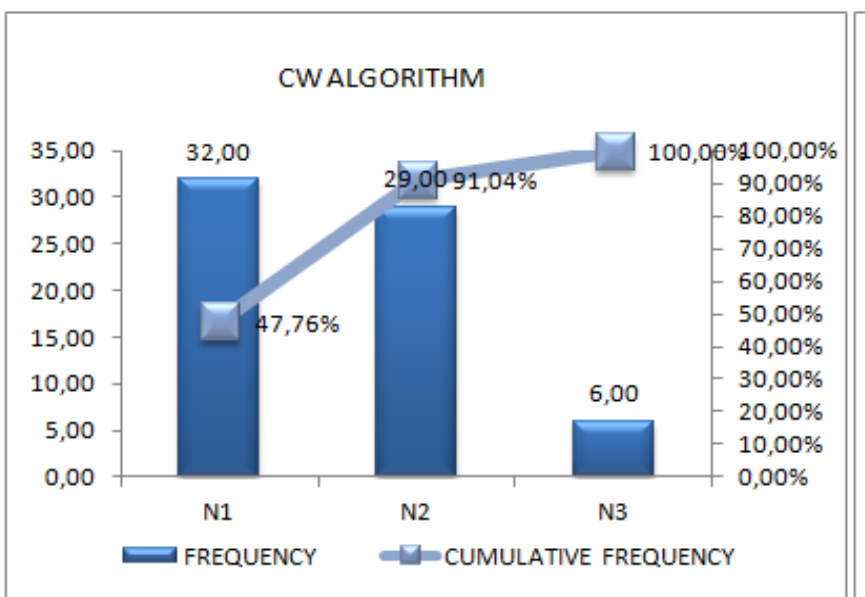

PROPOSAL OF ALGORITHM

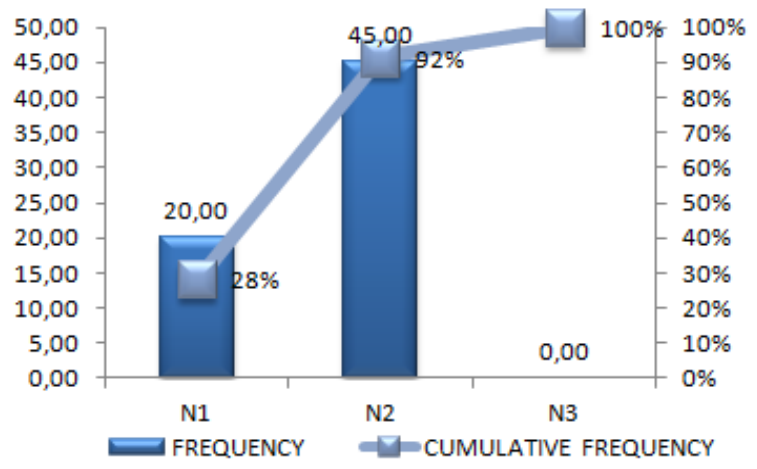

Figure 2. Comparison between Pareto Charts.

The proposed algorithm presented 12 single delivery routes (N1) less than Clarke and Wright's algorithm (1964), it was because the logic of the calculation aims to avoid single delivery routes instead of maximizing each route. In practice, two factors contributed for this: (a) to get a connection point for points with greater demand and (b) to distribute the amount of points per route more uniformly, so that the maximum points per route is two.

The amount of mistakes directly impacts on variability. Several authors stress the importance of analyzing this aspect. Dellareti Filho and Drumond (1994) emphasize the use of the normal distribution curves for analysis of variability. To those authors, this tool is suitable to describe characteristics of quality, whose variation is the result of the sum of errors arising from the process. It is obtained through the parameters: a) center of the curve (average); and b) dispersion (standard deviation) of distribution. Lourenço Filho (1976) states that the normal distribution indicates that a process is in control, not containing any point out of the settled limits. If the variability becomes abnormal, there are indications that the process has changed and got out of control.

The results of journey time and travelled distance can be seen in the graphs of the distribution of time and distance (Figures 3, 4, 5 and 6).

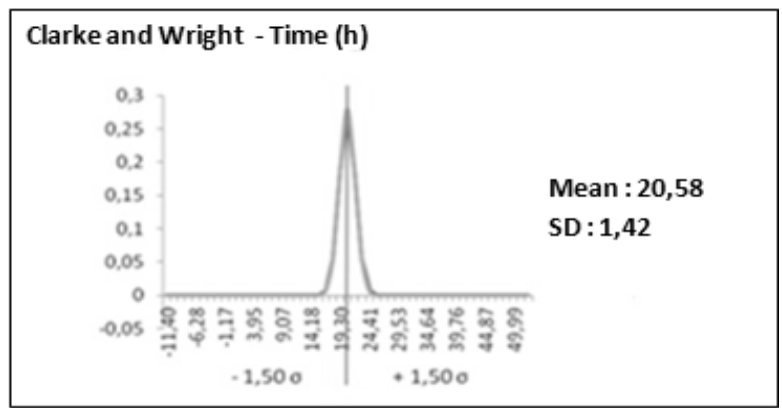

Figure 3. CW Algorithm: time in hours. 
Proposal of Algorithm - Time (h)

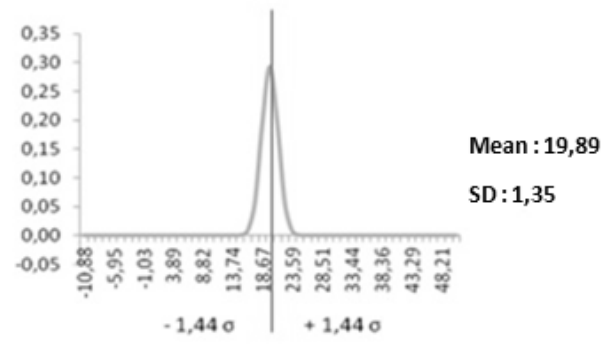

Figure 4. The Proposal of Algorithm: time in hours.

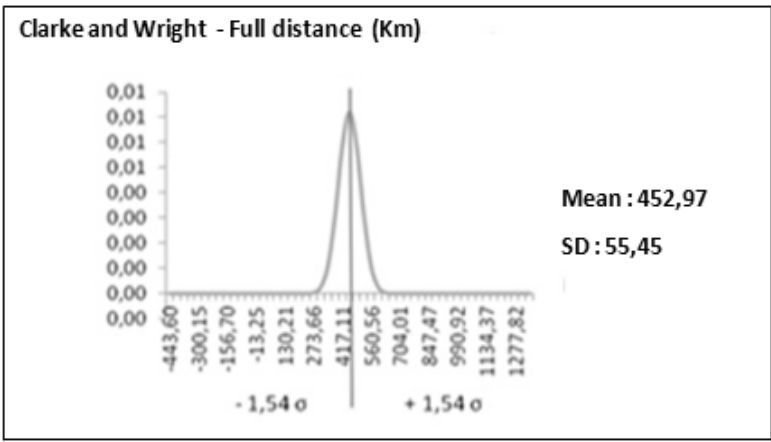

Figure 5. CW Algorithm: distance in kilometers.

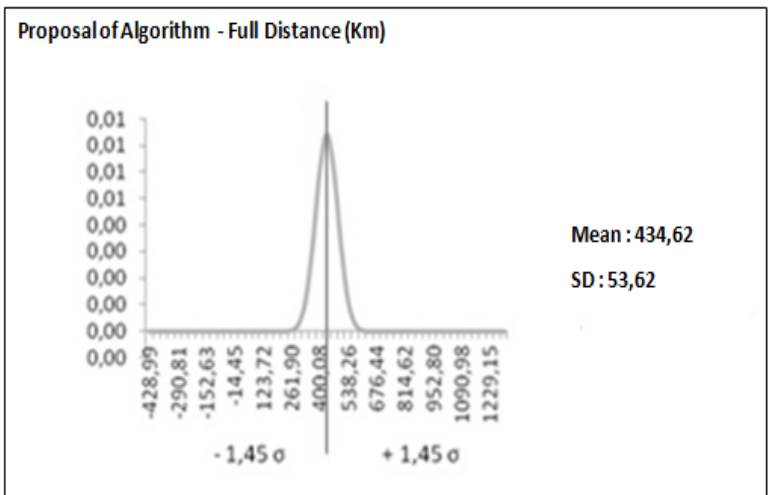

Figure 6. The Proposal of Algorithm: distance in kilometers.

The results show that the proposed algorithm presented less dispersed data, since it was able to reduce the standard deviation of the values of time and distance travelled.
According to Davis, Aquilano and Chase (2001), the main objective of the statistical quality control is to keep a process under control, with results that are within tolerable limits. To check the sigma level of both processes, the following indexes were calculated: dpu (defects per unit), dpo (defects per opportunity), dpmo (defects per million opportunities), RTY (probability of zero defects in a multi-step process, where each system consists of a step) and the yield of the process, as Table 8.

Table 8. Mapping and comparison between results.

\begin{tabular}{|l|r|l|r|}
\hline \multicolumn{3}{|c|}{ Clarke and Wright } & \multicolumn{2}{c|}{ Proposal of Algorithm } \\
\hline N units & 67,00 & N units & 65,00 \\
\hline N defects & 32,00 & N defects & 20,00 \\
\hline N opportunities & 67,00 & N opportunities & 65,00 \\
\hline DPU & 0,48 & DPU & 0,31 \\
\hline DPO & 0,007 & DPO & 0,005 \\
\hline DPMO & $7.128,54$ & DPMO & $4.733,73$ \\
\hline RTY (\%) & 0,0068 & RTY (\%) & 0,0048 \\
\hline Performance process (\%) & $52,24 \%$ & Performance process ( \%) & 69,23 \\
\hline Sigma Level & 3,980 & Sigma Level & 4,250 \\
\hline
\end{tabular}

The data showed that the proposed algorithm has much lower rates of defects per unit of defects per opportunity the higher income in the process (16.99\% higher). The RTY index demonstrates that the likelihood of this algorithm to obtain zero error (single delivery routes) is $4.75 \%$. Nonetheless, the RTY of the Clarke and Wright's algorithm (1964) is $0.68 \%$. 
To measure the sigma level of each process the scale proposed by Lucier and Sechadri (2001) was used, that performs sorting through the value of dpmo (defects per million opportunities). The proposed algorithm gained 4.25 level $\sigma$ and the Clarke and Wright's algorithm (1964) that was classified as level $3.98 \sigma$. This means that the proposal has obtained results of higher level of quality.

To illustrate, in a more didactical way, the differences between the routes, Figure $X$ shows the delivery paths obtained by the use of Clarke and Wright's model (1964) given a total demand of 18.5 tones. We can notice that the delivery system has the pattern of: 2 routes containing links among 3 delivery points each, 0 routes containing links between 2 delivery points each and 4 delivery points to only 1 point. In which we obtained a total distance course of 426.37 $\mathrm{km}$ and a total journey time of 19.95 hours, as Figure 7.

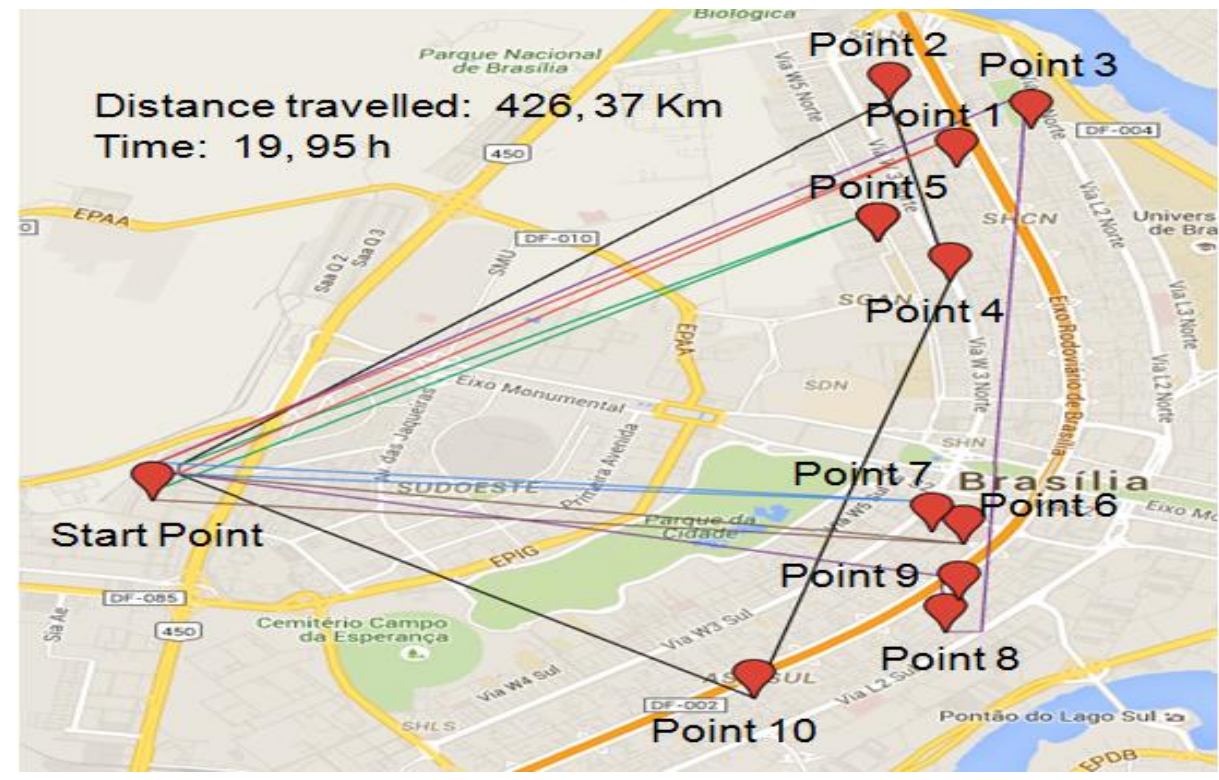

Figure 7. Delivery paths obtained by the use of Clarke and Wright's model (1964).

Given the same problem restrictions, the model proposed by the article obtained a system with a pattern of: 0 routes containing links among 3 delivery points each; 5 routes containing links between 2 delivery points each and 0 delivery routes to only 1 point. In which obtained a total distance course of $395.26 \mathrm{~km}$ and a total journey time of 18.77 hours, according to figure 8. 
Figure 8. Delivery paths obtained by the use of Proposal of Algorithm.

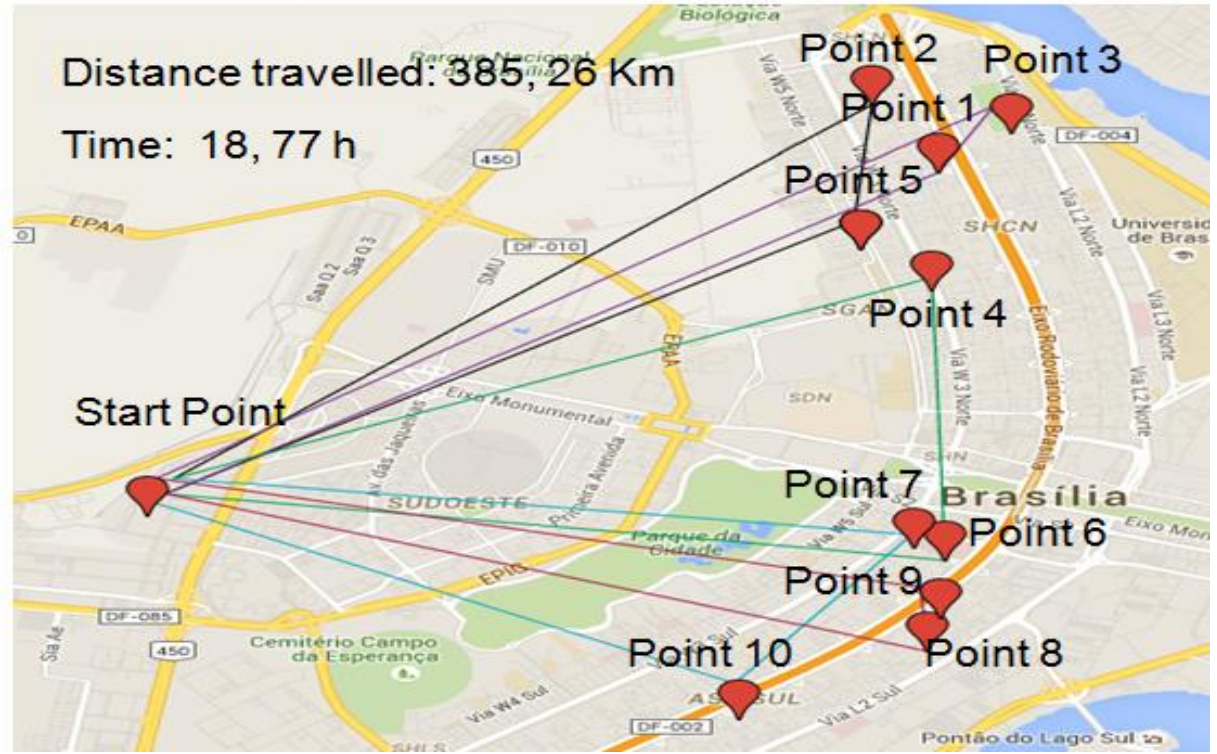

In this comparison, the model proposed achieved a reduction of $41.11 \mathrm{~km}$ of total distance course and 1.18 hours in total journey time in relation to Clarke and Wright's model (1964)

\section{FINAL CONSIDERATIONS}

It was possible to observe that the relationship between the ability to offer services and demand is one factor that exerts enough influence on the results of Clarke and Wright's algorithm (1964). By means of simulations, it was observed that each unique additional delivery route reduced the ability of system optimization.

Given this, one can state that in certain problems, to avoid the routes of single delivery routes is as important as making the decisions that provide the greatest gains in distance. That is due to the inefficiency of delivery routes which can only nullify the effectiveness of decisions taken by "hierarchy of gains in distance".

Comparisons show that the proposed algorithm demonstrates the best results on the simulations relating to total 18.5 demands, 19.0, 20.0 19.5, 20.5, 21.5 21.0, 23.0, and tons, in which the "Sigma" quality level is higher than the one obtained through Clarke and Wright's algorithm (1964). This evidences that the algorithm has functionality and can be used for comparative purposes.

However, there is no sufficient evidence to refute the applicability of Clarke and Wright's algorithm (1964), since this find the best decision for delivery systems with a total of 18.0, 22.0 demands and 22.5 tons.

Therefore, it can be concluded that the proposed algorithm has a reliability level greater than Clarke and Wright's (1964) for this simulated context. Still, it is noteworthy 
that the proposed algorithm is not a substitute for logic, but an alternative solution.

\section{REFERENCES}

BALLOU, R. Gerenciamento da cadeia de suprimentos/logística empresarial. 5. ed. Porto Alegre: Bookman, 2006.

BAÑUELAS, R.; ANTONY, J. Critical success factors for the successful implementation of six sigma projects in organizations. The TQM Magazine, v. 14, n. 2, p. 92-99, 2002. https://doi.org/10.1108/0954478021041670 $\underline{2}$

BENJAMIN, J. An Analysis of Inventory and Transportation Costs in a Constrained Network. Transportation Science, v. 23, n. 3, p. 177-183, 1989.

https://doi.org/10.1287/trsc.23.3.177

BREYFOGLE, F. W. Implementing Six Sigma, smarter solutions - Using Statistical Methods. New York: Wiley, 1999.

CAMPBELL, A. M.; SAVELBERGH, M. W. P. A Decomposition Approach for the InventoryRouting Problem. Transportation Science, v.38, n.4, p.488-502, 2004. https://doi.org/10.1287/trsc.1030.0054

CHIEN, T. W.; BALAKRISHNAN, A.; WONG, R. T. An Integrated Inventory Allocation and Vehicle Routing Problem. Transportation Science, v. 23, n. 2, p. 67-76, 1989. https://doi.org/10.1287/trsc.23.2.67
CLARKE, G.; WRIGHT, J. W. Scheduling of Vehicles from a Central Depot to a Number of Delivery Points. Operations Research, v. 12, n. $4, \quad$ p. $568-581,1964$. https://doi.org/10.1287/opre.12.4.568 CUNHA, C. B.; BONASSER, U. O.; ABRAHÃO, F. T. M. Experimentos computacionais com heurísticas de melhorias para o problema do caixeiro viajante. Rio Grande do Norte: Associação Nacional de Pesquisa e Ensino em Transportes-ANPET, 2002.

DAVIS, M. M.; AQUILANO N. J.; CHASE R. B. Fundamentos da administração da produção. 3. ed. Porto Alegre: Bookman, 2001.

DELLARETI FILHO, O. D.; DRUMOND, F. B. Itens de controle e avaliação de processos. Belo Horizonte: Fundação Christiano Ottoni, 1994.

DROR, M.; LEVY, L. A. Vehicle routing improvement algorithm comparison of a "Greedy" and a matching implementation for inventory routing. Computers and Operations Research, v. 13, n. 1, p. 33-45, 1986.

FOLARON, J. The evolution of Six Sigma. Six Sigma Forum Magazine, v. 2, n. 4, p. 35-45, 2000

HAHN, G. J.; DOGONAKSOV, N.; HOERLI, R. The evolution of six sigma. Quality Engineering, v. 2, n. 3, p. 317-326, 2000 https://doi.org/10.1080/0898211000896259 
HALL, R. W.; PARTYKA, J. G. On the road to efficiency. OR/MS Today, p.38-47, 1997.

HARRY, M. J. Six sigma: A breakthrough strategy for profitability. Quality Progress, Milwaukee, v. 31, n.5, p. 60-64, 1998.

HENSHER, D. A.; BUTTON , K, J. Handbook of transport modelling. 2. ed. UK: Emerald Group, 2008.

JOHSON, D. S.; MCGEOCH, L. A. The traveling salesman problem : a case study in local optimization. Local Search in Combinatorial Optimization, 1995.

LAPORTE, G. et al. Classical and modern heuristics for the vehicle routing problem.

Internacional Transactions in Operations in Operational Research, v. 7 , n. $4 / 5$, p. $285-$ 300, 2000. https://doi.org/10.1111/j.14753995.2000.tb00200.x

LARSON, R. C. Transporting Sludge to the 106-Mile Site: An Inventory/Routing Model for Fleet Sizing and Logistics System Design. Transportation Science, v. 22, n. 3, p. 186198, 1998.

\section{https://doi.org/10.1287/trsc.22.3.186}

LOBOS, J. Qualidade através das pessoas. 9. ed. São Paulo: Instituto da Qualidade, 1991.

LUCAS, J. M. The Essential Six Sigma. Quality Progress, Milwaukee, v. 35, n. 1, p. 27-31, 2002.

LUCIER, G. T; SESHADRIS, S. Ge Takes Six Sigma Beyonde the Bottom Line. Strategic Finance, Montvale, v. 82, n.11, p.40-46, 2001.
MARASH, S. A. Six Sigma: Business Results Through Innovation. In: QUALITY CONGRESS.ASQ"S， 54., $\quad$ Proceedings... Milwaukee, 2000. p. 627-630.

MONTGOMERY, D. C. Introdução ao controle estatístico da qualidade. 4. ed. Rio de Janeiro: LTC, 2004. 513p.

PANDE, P. S.; NEUMAN, R. P.; CAVANAGH, R. R. Estratégia Seis Sigma: como a GE, a Motorola e outras Grandes empresas estão aguçando seu desempenho. Rio de Janeiro: Qualitymark, 2002.472p.

PFEIFER, T.; REISSIGER, W.; CANALES, C. Integrating six sigma with quality management systems. The TQM Magazine, v. 16, n. 4, p. 241-249, 2004. https://doi.org/10.1108/0954478041054189 $\underline{1}$

SPERANZA, M.G.; UKOVICH, W. Minimizing Transportation and Inventory Costs for Several Products on a Single Link. Operations Research, v. 42, ํ․ 5, pp. 879-894, 1994. https://doi.org/10.1287/opre.42.5.879 WHEELER, J.M. Getting Starded: Six Sigma Control of Chemical Operations. Management, 2002.

WERKEMA, C. Criando a cultura Seis Sigma. Rio de Janeiro: QualityMark, 2002.

WESSEL, G.; BURGUER, P. Six Sigma for small and medium-sized enterprises. The TQM Magazine, v. 16, n. 4, p. 264-272, 2004. https://doi.org/10.1108/0954478041054191 $\underline{8}$ 


\section{ANNEX 1}

\section{Below follows a description of paths obtained}

through the simulations.

Where: the number 0 is the warehouse (start

point). The other numbers represents the delivery points.

\begin{tabular}{|c|c|c|c|}
\hline & & CW ALGORITHM & PROPOSAL OF ALGORITHM \\
\hline ROUTE 1 & 18,0 (ton) & $\begin{array}{c}(0-3-8-9-0) ;(0-6-10-0) ;(0-2-5-0 \\
) ;(0-4-7-0) ;(0-1-0)\end{array}$ & $\begin{array}{c}(0-1-3-0) ;(0-4-6-0) ;(0-2-5-0) ; \\
(0-8-9-0) ; \quad(0-7-10-0)\end{array}$ \\
\hline ROUTE 2 & 18,5 (ton) & $\begin{array}{c}(0-3-8-9-0) ;(0-2-4-10-0) \\
(0-1-0) ;(0-5-0) ;(0-6-0) ;(0-7-0)\end{array}$ & $\begin{array}{c}(0-1-3-0) ;(0-4-6-0) ;(0-2-5-0) \\
(0-8-9-0) ;(0-7-10-0)\end{array}$ \\
\hline ROUTE 3 & 19,0 (ton) & \begin{tabular}{|c|}
$\begin{array}{c}(0-2-3-8-0) ;(0-9-10-0) ;(0-4-5-0) ; \\
(0-1-0) ;(0-6-0) ;(0-7-0)\end{array}$ \\
\end{tabular} & $\begin{array}{c}(0-1-3-0) ;(0-4-6-0) ;(0-2-5-0) \\
(0-8-9-0) ;(0-7-10-0)\end{array}$ \\
\hline ROUTE 4 & 19, 5 (ton) & $\begin{array}{c}(0-2-3-8-0) ;(0-9-10-0) ;(0-4-5-0) \\
;(0-1-0) ;(0-6-0) ;(0-7-0)\end{array}$ & $\begin{array}{c}(0-1-3-0) ;(0-4-6-0) ;(0-2-5-0) \\
(0-8-9-0) ;(0-7-10-0)\end{array}$ \\
\hline ROUTE 5 & 20,0 (ton) & $\begin{array}{c}(0-3-4-8-0) ;(0-9-10-0) ;(0-2-5-0) \\
\quad(0-1-0) ;(0-7-0) ;(0-6-0)\end{array}$ & $\begin{array}{c}(0-3-6-0) ;(0-2-5-0) ;(0-8-9-0) \\
\quad(0-7-10-0) ;(0-1-0) ;(0-4-0)\end{array}$ \\
\hline ROUTE 6 & 20,5 (ton) & $\begin{array}{l}(0-3-8-0) ;(0-9-10-0) ;(0-2-5- \\
0) ;(0-4-7-0) ;(0-1-0) ;(0-6-0)\end{array}$ & $\begin{array}{l}(0-3-6-0) ;(0-2-5-0) ;(0-8-9-0) \\
(0-7-10-0) ;(0-1-0) ;(0-4-0)\end{array}$ \\
\hline ROUTE 7 & 21,0 (ton) & $\begin{array}{c}(0-3-8-0) ;(0-9-10-0) ;(0-2-5-0) \\
(0-4-7-0) ;(0-1-0) ;(0-6-0)\end{array}$ & $\begin{array}{c}(0-3-6-0) ;(0-2-5-0) ;(0-8-9-0) \\
(0-7-10-0) ;(0-1-0) ;(0-4-0)\end{array}$ \\
\hline ROUTE 8 & 21,5 (ton) & $\left(\begin{array}{l}(0-3-8-0) ;(0-9-10-0) ;(0-4-7-0) \\
(0-1-0) ;(0-6-0) ;(0-2-0) ;(0-5-0)\end{array}\right.$ & $\begin{array}{c}(0-3-6-0) ;(0-8-9-0) ;(0-2-10-0) \\
(0-4-7-0) ;(0-5-0) ;(0-1-0)\end{array}$ \\
\hline ROUTE 9 & 22,0 (ton) & $\begin{array}{c}(0-3-8-0) ;(0-9-10-0) ;(0-4-7-0) \\
(0-1-0) ;(0-6-0) ;(0-2-0) ;(0-5- \\
0)\end{array}$ & $\begin{array}{l}(0-3-6-0) ;(0-9-10-0) ;(0-2-7-0) \\
(0-1-0) ;(0-5-0) ;(0-8-0) ;(0-4-0)\end{array}$ \\
\hline ROUTE 10 & 22,5 (ton) & $\begin{array}{c}(0-3-8-0) ;(0-9-10-0) ;(0-4-7-0) \\
;(0-1-0) ;(0-6-0) ;(0-2-0) ;(0-5- \\
0)\end{array}$ & $\begin{array}{l}(0-3-6-0) ;(0-4-7-0) ;(0-9-10-0) \\
(0-1-0) ;(0-5-0) ;(0-8-0) ;(0-2-0)\end{array}$ \\
\hline ROUTE 11 & 23,0 (ton) & $\begin{array}{l}(0-2-3-0) ;(0-9-10-0) ;(0-4-7-0) \\
;(0-1-0) ;(0-5-0) ;(0-6-0) ;(0-8-0)\end{array}$ & $\begin{array}{l}(0-3-4-0) ;(0-2-9-0) ;(0-7-10-0) ; \\
(0-1-0) ;(0-6-0) ;(0-5-0) ;(0-8-0)\end{array}$ \\
\hline
\end{tabular}

